\title{
RESEARCH
}

Open Access

\section{Integrin a2 gene polymorphism is a risk factor of coronary artery lesions in Chinese children with Kawasaki disease}

Jia Yuan ${ }^{1 \dagger}$, Zhiyong Jiang ${ }^{2 \dagger}$, Meiai $\mathrm{Li}^{3+}$, Wei $\mathrm{Li}^{i^{\dagger+}}$, Xueping $\mathrm{Gu}^{2}$, Zhouping Wang ${ }^{1}$, Lei $\mathrm{Pi}^{4}$, Yufen Xu ${ }^{4}$, Huazhong Zhou ${ }^{4}$, Baidu Zhang ${ }^{3}$, Qiulian Deng ${ }^{3}$, Yanfei Wang ${ }^{1}$, Ping Huang ${ }^{1}$, Li Zhang ${ }^{1 *}$ and Xiaoqiong Gu ${ }^{5^{*}}$

\begin{abstract}
Background: Kawasaki disease (KD) is a systemic vasculitis, and the formation of coronary artery lesions(CAL) is its most common sequela. Both genetic and environmental factors are considered to be important factors of in KD. Integrin a2 (ITGA2) is a transmembrane receptor that is associated with susceptibility to several diseases, but its relevance to $\mathrm{KD}$ with $\mathrm{CAL}$ is unclear.

Methods: We genotyped ITGA2 rs1126643 in 785 KD patients with the CAL and no-CAL(NCAL) (300 patients with CAL, and 485 age- and sex-matched patients with NCAL). OR (95\% Cl) and adjusted OR (95\% Cl) were used to evaluate the intensity of the association.

Results: We found a significantly increased risk of KD with CAL associated with ITGA2 rs1126643 genotypes (CT vs CC: adjusted $\mathrm{OR}=1.57,95 \% \mathrm{Cl}=1.16-2.12, P=0.0032 ; \mathrm{CT} / \mathrm{TT}$ vs $\mathrm{CC}$ : adjusted $\mathrm{OR}=1.49,95 \% \mathrm{Cl}=1.12-2.00, P=$ $0.0068 ; \mathrm{T}$ vs $\mathrm{C}$ : adjusted $\mathrm{OR}=1.66,95 \% \mathrm{Cl}=1.16-2.51, P=0.0165)$. Moreover, we found that carriers of the $\mathrm{CT} / \mathrm{TT}$ genotype had a significant risk of KD with coronary artery lesion susceptibility for children $\leq 60$ months of age, and the CT/TT genotype was significantly associated with an increased risk of SCAL formation and MCAL formation when compared with the CC genotype.
\end{abstract}

Conclusion: ITGA2 rs1126643 was associated with increased susceptibility and severity of CAL in KD.

Keywords: Kawasaki disease, ITGA2, Genetic susceptibility, Polymorphism

\footnotetext{
*Correspondence: Zhangliheart2016@163.com; guxiaogiong@gwcmc.org

${ }^{\dagger}$ Jia Yuan, Zhiyong Jiang, Meiai Li and Wei Li contributed equally to this work.

'Department of Cardiology, Guangzhou Women and Children's Medical Center, Guangzhou Medical University, Guangzhou 510623, Guangdong, China

${ }^{5}$ Department of Blood Transfusion, Clinical Biological Resource Bank and Clinical Lab, Guangzhou Institute of Pediatrics, Guangzhou Women and Children's Medical Center, Guangzhou Medical University, Guangzhou 510623, Guangdong, China

Full list of author information is available at the end of the article
}

(C) The Author(s). 2021 Open Access This article is licensed under a Creative Commons Attribution 4.0 International License, which permits use, sharing, adaptation, distribution and reproduction in any medium or format, as long as you give appropriate credit to the original author(s) and the source, provide a link to the Creative Commons licence, and indicate if changes were made. The images or other third party material in this article are included in the article's Creative Commons licence, unless indicated otherwise in a credit line to the material. If material is not included in the article's Creative Commons licence and your intended use is not permitted by statutory regulation or exceeds the permitted use, you will need to obtain permission directly from the copyright holder. To view a copy of this licence, visit http://creativecommons.org/licenses/by/4.0/ The Creative Commons Public Domain Dedication waiver (http://creativecommons.org/publicdomain/zero/1.0/) applies to the data made available in this article, unless otherwise stated in a credit line to the data. 


\section{Background}

Kawasaki disease (KD) is a systemic vasculitis first described by Dr. Kawasaki in 1974 in Japan [1]. It primality affects children below 5 years old, especially in Asian countries. The incidence of $\mathrm{KD}$ is highest in Japan, Korea and Taiwan ranging from 66/100,000 to 234/100, 000 in children younger than 5 years old [2,3]. The exact etiology of KD is not known [4]. Both genetic and environmental factors have been reported to play important role in KD [5]. The most common sequel of KD is coronary artery lesions (CAL), which is known to predominantly occur in young children $(84 \% \sim 86 \%$ of all cases occur in children between 6 months and 5 years of age) with a male predominance (approximately $1.5 \sim 1.8$ times higher than females) [6, 7]. CAL included coronary artery dilation, aneurysms, or fistula formation. All patients were identified only by echocardiography.

Antiplatelet therapy is routinely applied in KD treatment. Elevated platelet counts often develop in the acute phase of KD. This causes hyperplatelet function in which platelets become adherent, deformed, aggregates and release various cytokines and inflammatory factors. As a consequence, blood hypercoagulates causing vascular endothelial injury, collagen exposure, and triggers chemotaxis of various cytokines, all of which results in the formation of vascular inflammatory lesions [8]. Lowdose aspirin was recommended to prevent platelet activation and aggregation. All the patients received low doses of aspirin( $3-5 \mathrm{mg} / \mathrm{kg} /$ day).Integrin $\alpha 2$ (ITGA2), which encodes the alpha subunit of the transmembrane receptor for collagens and related proteins, is located on chromosome 5q23-31 [9]. The encoded protein forms a heterodimer with a beta subunit responsible for adhesion of platelets and other cell types to the extracellular matrix. KD is defined as a vascular injury disease similar to arterial thrombosis. Mutations of the ITGA2 gene have been associated with vascular injury. It is therefore likely that a correlation exists between ITGA2 and KD. A meta-analysis suggested that ITGA2 rs1126643 affected susceptibility to aspirin insensitivity [10]. The average frequency of the ITGA2 gene rs1126643-T allele was $40.77 \%$ in Caucasian patients with aspirin insensitivity but was $58.58 \%$ in Chinese patients [10]. Here, we investigated whether ITGA2 SNP (rs1126643) polymorphism influences susceptibility to CAL in a cohort of $785 \mathrm{KD}$ patients with or without CAL in the Chinese population.

\section{Materials and methods}

\section{Subjects}

A total of 300 patients with KD coronary artery lesions, diagnosed in line with the criteria of the American Heart Association in 2004 [11] who were receiving treatment in the Guangzhou Women and Children's Medical
Center, were enrolled. Additionally, 485 age- and sexmatched children patients with no-CAL(NCAL) were recruited in the same hospital, between February 2014 and February 2017. About $2 \mathrm{~mL}$ blood was collected from each participant for genomic DNA extraction (Qiagen, Dusseldorf, Germany). Informed consent was obtained from each participant's guardian. This study was approved by the Institutional Committee of Guangzhou Women and Children's Medical Center (2014073009).

\section{SNP selection and genotyping}

Genomic DNA was extracted from peripheral blood samples for genotypic analysis of the SNPs (rs 11,226, 643) of interest in the ITGA2 gene. Functional polymorphism was carried out based on a thorough evaluation of polymorphisms associated with vasculopathy $[10,11]$. This was performed following methods reported previously [12]. Genomic DNA was extracted using the TIANamp Blood DNA Kit (Qiagen, Dusseldorf, Germany). The DNA samples were kept at $-80^{\circ} \mathrm{C}$ until batch genotyping. Genotyping of the DNA was conducted via PCR using multiple gene-specific primer pairs targeting ITGA2 (rs1126643: forward GTGTTTAA CTTGAACACATAT/ reverse AACTTG CATATTTT GCTT). The volume of the PCR mixture was $10 \mu \mathrm{l}(2 \times$ multiplex PCR mix + PCR primer pool and template DNA). The PCR protocol consisted of the following: $95^{\circ} \mathrm{C}$ for $3 \mathrm{~min} ; 15$ cycles of $95^{\circ} \mathrm{C}$ for $20 \mathrm{~s}, 58^{\circ} \mathrm{C}$ for $90 \mathrm{~s}$, and $72{ }^{\circ} \mathrm{C}$ for $30 \mathrm{~s}$; and $72{ }^{\circ} \mathrm{C}$ for 1 min using a GeneAmp PCR System 9700 (Thermo Fisher Scientific). The PCR products were subjected to massive parallel sequencing using an Ion Proton system (Life Technologies, CA, USA).

\section{Statistical analysis}

The frequency distribution of the polymorphism and the demographic variables between $\mathrm{KD}$ with CAL and NCAL were compared using the $\chi^{2}$ test. The association of the ITGA2 rs1126643 $\mathrm{C}>\mathrm{T}$ polymorphism with KD susceptibility was evaluated by calculating the odds ratio (OR) and 95\% confidence interval (CI) using unconditional multivariate logistic regression analyses. Stratified analysis was based on coronary artery outcomes, age and sex, and $P$-values $<0.05$ were considered statistically significant. Statistical analyses were performed using SAS software (Version 9.3; SAS Institute, Cary, NC, USA).

\section{Results}

\section{Characteristics of the study population}

The demographic characteristics of the KD patients with and without CAL are summarized in Table 1 . The average age of patients was 28.48 months ( \pm 29.01 , range $=1-166$ months) for CAL and 31.23 months $( \pm$ 23.20 , range $=1-110$ months) for NCAL. There was no 
Table 1 Characteristics of KD cases with the CAL and NCAL group

\begin{tabular}{llll}
\hline Variables & CAL & NCAL & P-value $^{\mathbf{a}}$ \\
\hline Age range, month & $1-166$ & $1-110$ & \\
Mean \pm SD & $28.48 \pm 29.01$ & $31.23 \pm 23.20$ & \\
$\quad \leq 60$ & $271(90.33 \%)$ & $425(87.63 \%)$ & 0.2411 \\
$>60$ & $29(9.67 \%)$ & $60(12.37 \%)$ & \\
sex & & & \\
$\quad$ Male & $220(73.33 \%)$ & $325(67.01 \%)$ & 0.0603 \\
$\quad$ Female & $80(26.67 \%)$ & $160(32.99 \%)$ & \\
Severity of CAL & & & \\
$\quad$ SCAL & & & \\
MCAL $^{\text {c }}$ & $188(62.67 \%)$ & & \\
GCAL $^{\text {d }}$ & $63(21.00 \%)$ & & \\
\hline
\end{tabular}

${ }^{a}$ Two-sided $\mathrm{x} 2$ test for distributions between Kawasaki disease patients with the CAL and NCAL. ${ }^{b}$ Kawasaki disease patients with coronary artery dilatations/small aneurysms. ${ }^{\mathrm{C}}$ Kawasaki disease patients with coronary artery medium aneurysms. ${ }^{d}$ Kawasaki disease patients with coronary artery giant aneurysms

significant difference in age $(P=0.2411)$ or $\operatorname{sex}(P=$ 0.0603 ) between CAL and NCAL groups. Twodimensional echocardiography revealed that 188 (62.67\%) patients developed coronary artery dilatations/ small aneurysms (SCAL), 63 (21.00\%) developed coronary artery medium aneurysms (MCAL), and 49 (16.33\%) developed giant coronary artery aneurysms (GCAL).

\section{Association of ITGA2 gene polymorphism and KD with CAL susceptibility}

The frequency distribution of the SNP polymorphism in the Kawasaki disease patients with and without CAL is shown in Table 2. The rs1126643 genotype showed increased risk of KD patients with CAL after adjustment for age and sex (CT vs CC: adjusted $\mathrm{OR}=1.57,95 \% \mathrm{CI}=$ $1.16-2.12, P=0.0032 ; \mathrm{CT} / \mathrm{TT}$ vs $\mathrm{CC}$ : adjusted $\mathrm{OR}=$ $1.49,95 \% \mathrm{CI}=1.12-2.00, P=0.0068 ; \mathrm{T}$ vs $\mathrm{C}$ : adjusted $\mathrm{OR}=1.66,95 \% \mathrm{CI}=1.16-2.51, P=0.0165)$. No other significant associations were detected. As a result, the harmful genotype used for the calculation was ITGA2 rs1126643 CT/TT.

\section{Stratified analysis for polymorphism and Kawasaki disease susceptibility}

The association of ITGA2 gene (rs1126643) polymorphism with KD coronary artery lesion susceptibility was further determined in stratified analysis by age, sex and severity of CAL (Table 3). Results showed that carriers of the CT/TT genotype had a significantly higher risk of KD coronary artery lesion especially for children $\leq 60$ months of age (adjusted $\mathrm{OR}=1.44,95 \% \mathrm{CI}=1.06-1.96$, $P=0.0199$ ) and males (adjusted $\mathrm{OR}=1.50,95 \% \mathrm{CI}=$ $1.06-2.11, P=0.0218)$. The CT/TT genotype was significantly associated with an increased risk of SCAL (adjusted $\mathrm{OR}=1.47,95 \% \mathrm{CI}=1.04-2.08, P=0.0277$ ) and MCAL (adjusted $\mathrm{OR}=1.72,95 \% \mathrm{CI}=1.01-2.93, \quad P=$ 0.0451) compared with carriers of the CC genotype.

\section{Discussion}

Here, we reveal an association of the ITGA2 gene (rs1126643) polymorphism with the risk of KD in 300 patients with CAL and 485 patients with NCAL. Specifically, the ITGA2 rs $1126643 \mathrm{CT} / \mathrm{TT}$ was associated with an increased risk of KD patients with CAL, especially in children $\leq 60$ months of age and males. Stratified analysis demonstrated that the ITGA2 rs1126643 CT/TT variant elevated the risk of KD progressing into SCAL and MCAL. To our knowledge, this is the first study to show that ITGA2 rs1126643 polymorphism is associated with KD coronary artery lesion susceptibility.

Integrins are adhesion molecules that promote platelet aggregation, hence the formation of blood clots [13]. ITGA2 is an important platelet receptor for collagen and regulates platelet activation by facilitating platelet adhesion and aggregation to the exposed surface of the subendothelial collagen fiber [14]. The gene encoding ITGA2 contains a number of polymorphisms, such as

Table 2 Genotype frequency distribution of the rs1126643 polymorphism in KD cases with the CAL and NCAL

\begin{tabular}{|c|c|c|c|c|c|c|c|}
\hline Genotype & CAL $(n=300)$ & NCAL $(n=485)$ & $P$-value ${ }^{a}$ & OR (95\% Cl) & $P$-value & Adjusted OR (95\% Cl) & Adjusted $P$-value ${ }^{b}$ \\
\hline \multicolumn{8}{|c|}{ ITGA2/rs1126643 C> T } \\
\hline CC & $138(46.00 \%)$ & 273 (56.29\%) & & 1.00 & & 1.00 & \\
\hline$C T$ & $146(48.67 \%)$ & $182(37.53 \%)$ & & $1.59(1.18-2.14)$ & 0.0025 & $1.57(1.16-2.12)$ & 0.0032 \\
\hline$\pi$ & $16(5.33 \%)$ & 30 (6.19\%) & & $1.06(0.56-2.00)$ & 0.8697 & $1.03(0.54-1.95)$ & 0.9374 \\
\hline Additive & & & 0.0089 & $1.29(1.02-1.64)$ & 0.0342 & $1.28(1.01-1.62)$ & 0.0443 \\
\hline Dominant & $162(54.00 \%)$ & 212 (43.71\%) & 0.0050 & $1.51(1.13-2.02)$ & 0.0051 & $1.49(1.12-2.00)$ & 0.0068 \\
\hline Recessive & $284(94.67 \%)$ & 455 (93.81\%) & 0.6193 & $0.85(0.46-1.60)$ & 0.6216 & $0.83(0.45-1.56)$ & 0.5675 \\
\hline$C$ & $422(70.33 \%)$ & $728(75.05 \%)$ & 0.0409 & 1.00 & & 1.00 & \\
\hline T & 178 (29.67\%) & 242 (24.95\%) & & $1.63(1.08-2.47)$ & 0.0194 & $1.66(1.10-2.51)$ & 0.0165 \\
\hline
\end{tabular}

${ }^{\mathrm{a}}$ Two-sided $\mathrm{x} 2$ test for distributions between Kawasaki disease patients with the CAL and NCAL. ${ }^{\mathrm{b}}$ Adjusted for age and sex status in logistic regress models 
Table 3 Stratification analysis of rs1126643 polymorphism in KD cases with the CAL and NCAL

\begin{tabular}{|c|c|c|c|c|c|c|c|}
\hline \multirow[t]{2}{*}{ Variables } & \multicolumn{2}{|c|}{ rs1126643 (Cases/Controls) } & \multirow[t]{2}{*}{$P$-value ${ }^{a}$} & \multirow[t]{2}{*}{ OR $(95 \% \mathrm{Cl})$} & \multirow[t]{2}{*}{$P$-value } & \multirow{2}{*}{$\begin{array}{l}\text { Adjusted OR } \\
(95 \% \mathrm{Cl})\end{array}$} & \multirow{2}{*}{$\begin{array}{l}\text { Adjusted } \\
\text { P-value }^{b}\end{array}$} \\
\hline & $\mathrm{CC}$ & $\mathrm{CT} / \mathrm{TT}$ & & & & & \\
\hline \multicolumn{8}{|c|}{ Age, months } \\
\hline$\leq 60$ & $126 / 238$ & $145 / 187$ & 0.0143 & $1.47(1.08-1.99)$ & 0.0145 & $1.44(1.06-1.96)$ & 0.0199 \\
\hline$>60$ & $12 / 35$ & $17 / 25$ & 0.1328 & $1.98(0.81-4.88)$ & 0.1358 & $2.02(0.82-4.99)$ & 0.1292 \\
\hline \multicolumn{8}{|l|}{ sex } \\
\hline Male & $97 / 176$ & $123 / 149$ & 0.0210 & $1.50(1.06-2.11)$ & 0.0214 & $1.50(1.06-2.11)$ & 0.0218 \\
\hline Female & $41 / 97$ & $39 / 63$ & 0.1670 & $1.47(0.85-2.52)$ & 0.1669 & $1.52(0.88-2.61)$ & 0.1357 \\
\hline \multicolumn{8}{|c|}{ Severity of CAL } \\
\hline SCAL ${ }^{\mathrm{C}}$ & $86 / 273$ & $102 / 212$ & 0.0139 & $1.53(1.09-2.14)$ & 0.0142 & $1.47(1.04-2.08)$ & 0.0277 \\
\hline$M C A L^{d}$ & $27 / 273$ & $36 / 212$ & 0.0444 & $1.72(1.01-2.92)$ & 0.0457 & $1.72(1.01-2.93)$ & 0.0451 \\
\hline $\mathrm{GCAL}^{\mathbf{e}}$ & $25 / 273$ & $24 / 212$ & 0.4803 & $1.24(0.69-2.23)$ & 0.4797 & $1.23(0.68-2.22)$ & 0.4992 \\
\hline
\end{tabular}

${ }^{a}$ Two-sided $x 2$ test for distributions between Kawasaki disease patients with the CAL and NCAL. ${ }^{b}$ Adjusted for sex/age status in logistic regress models. ${ }^{c}$ Kawasaki disease patients with coronary artery dilatations/small aneurysms. ${ }^{d}$ Kawasaki disease patients with coronary artery medium aneurysms. ${ }^{\text {e }}$ Kawasaki disease patients with coronary artery giant aneurysms

ischemic stroke and idiopathic sudden sensorineural hearing loss (iSSNHL) $[15,16]$. ITGA2 has been implicated in thrombotic and arterial atherosclerotic disease. As a key member of the integrin family of adhesion molecules, ITGA2 mediates cell-cell, cell-matrix, and cellmatrix-cell adhesions [17]. It therefore affects various physiological and pathological processes such as inflammatory reactions, immune responses, atherosclerosis, and thrombosis [18]. KD is characterized by multisystem involvement and inflammation of all medium-sized arteries, including the coronary artery [19]. High infiltration of inflammatory cells in $\mathrm{KD}$ vascular tissues cause vascular damage during the acute febrile phase of $\mathrm{KD}$ [20]. In our study, we found that ITGA2 rs1126643 was a harmful factor with KD coronary artery lesions. To our knowledge, this is the first study to validate the association of ITGA2 rs1126643 with KD coronary artery lesions risk in a Chinese population. It may play a significant role in the pathogenesis of KD coronary artery lesions.

Although the etiology of KD is elusive, a genome-wide association study (GWAS) showed that single-nucleotide polymorphisms (SNPs) of AGT, NEBL, ITPKS, TGF- $\beta$, and KCNN2 may be modify the occurrence of CAL in KD [21-25]. To date, no study has explored the association of ITGA2 with KD coronary artery lesions. In the present study, we found that ITGA2 rs1126643 was associated with increased KD with coronary artery lesion susceptibility in the Chinese population. Stratified analysis showed that ITGA2 rs1126643 prevented the formation of SCAL and MCAL with KD.

Compared with the rs1126643 CC genotype, the harmful effect of the CT/TT variant genotype was more pronounced in children $\leq 60$ months of age and in males. This finding is consistent with results of other studies $[11,26]$. KD with CAL results in more apparent effects in young children below 60 months of age. The peak age of onset ranged from 9 to 11 months, and the male to female ratio was 1.5 to 1 [11,26, 27]. Our results indicate that ITGA2 gene polymorphism is among the important factors affecting CAL in children with KD with CAL. Therefore, children with KD CAL may be predisposed to CAL and should be monitored to initiate early prevention and treatment. However, these results are based on a small sample size. In addition, we only collected ethnicity, geographical factors, age and sex as cases and controls. However, other ITGA2 gene polymorphisms were not involved in this study.

These results underscore the need to monitor the possibility of CAL in children with KD based on ITGA2 gene mutation. Early initiation of interventions will reduce the risk of mortality caused by CAL in children with KD.

\section{Conclusion}

In summary, this study confirms that ITGA2 rs1126643 is associated with increased KD and coronary artery lesion susceptibility. However, future studies with larger sample sizes and practical experiments should be conducted to explore the roles of the ITGA2 gene in KD with coronary artery lesion susceptibility and severity.

\section{Abbreviations}

KD: Kawasaki disease; CAL: Coronary artery lesions; ITGA2: Integrin a2; SCAL: Kawasaki disease patients with coronary artery dilatations/small aneurysms; MCAL: Kawasaki disease patients with coronary artery medium aneurysms; GCAL: Kawasaki disease patients with coronary artery giant aneurysms; NCAL: No-CAL

\section{Acknowledgements}

The authors would like to thank the Clinical Biological Resource Bank of Guangzhou Women and Children's Medical Center for providing all clinical samples and the Guangdong Early Childhood Development Applied Engineering and Technology Research Center. 
The authors would like to thank the Clinical Biological Resource Bank of Guangzhou Women and Children's Medical Center for providing all the clinical samples. And thank the Guangdong Early Childhood Development Applied Engineering and Technology Research Center providing scientific research platform support.

\section{Authors' contributions}

All authors made important contributions to this work. J Y was responsible for the writing of the article. $Z-Y J$ and $M-A L$ were responsible for the design of the article. $W L^{*}$ was reviewed the literature and provided new ideas. $X-P$ G, Z-P W, L P, Y-F X, H-Z Zhou and B-D Z performed the experiments and collected data. Q-L D, Y-F W and P H analyzed the data, L Z and X-Q G designed the research study. All authors have read and approved the final version of this manuscript. * Wei Li is a newly added author. He reviewed the literature and provided a lot of new ideas.

\section{Funding}

This study was supported by the Guangdong Natural Science Fund, China, under grant number 2016A030313836; the Guangdong Science and Technology Project of China under grant number 2017A030223003; the Guangdong Traditional Chinese Medicine Scientific Research Fund, China, under grant numbers 20162112 and 20171204; the Guangzhou Science and Technology Program Project, China, under grant numbers 201607010011, 201707010270, 201804010035 and 201904010486; the Guangzhou Health and Health Science and Technology Project, China, under grant number 20191A011021and 20191A011033. Guangzhou Institute of Pediatrics/ Guangzhou Women and Children's Medical Center of internal fund, under grant number: GCP-2019-003, YIP-2019-050 and YIP-2019-003.

\section{Availability of data and materials}

Data sharing is not applicable to this article, as no datasets were generated or analyzed during the current study. Please contact the author for data requests.

\section{Ethics approval and consent to participate}

This study was performed with the ethics approval from the Institutional Committee of Guangzhou Women adn Children's Medical Center.

\section{Consent for publication}

Not applicable.

\section{Competing interests}

The authors report no conflicts of interest.

\section{Author details}

'Department of Cardiology, Guangzhou Women and Children's Medical Center, Guangzhou Medical University, Guangzhou 510623, Guangdong, China. ${ }^{2}$ Department of Blood Transfusion and Clinical Lab, Guangzhou Institute of Pediatrics, Guangzhou Women and Children's Medical Center, Guangzhou Medical University, Guangzhou 510623, Guangdong, China. ${ }^{3}$ Department of Clinical Lab, Guangzhou Institute of Pediatrics, Guangzhou Women and Children's Medical Center, Guangzhou Medical University, Guangzhou 510623, Guangdong, China. ${ }^{4}$ Department of Clinical Biological Resource Bank, Guangzhou Institute of Pediatrics, Guangzhou Women and Children's Medical Center, Guangzhou Medical University, Guangzhou 510623, Guangdong, China. ${ }^{5}$ Department of Blood Transfusion , Clinical Biological Resource Bank and Clinical Lab, Guangzhou Institute of Pediatrics, Guangzhou Women and Children's Medical Center, Guangzhou Medica University, Guangzhou 510623, Guangdong, China.

\section{Received: 16 April 2020 Accepted: 11 January 2021}

\section{Published online: 08 February 2021}

\section{References}

1. Kawasaki T, Kosaki F, Okawa S, Shigematsu I, Yanagawa H. A new infantile acute febrile mucocutaneous lymph node syndrome (MLNS) prevailing in Japan. Pediatrics. 1974:54:271-6.

2. Huang WC, Huang LM, Chang IS, Chang LY, Chiang BL, Chen PJ, et al. Epidemiologic features of Kawasaki disease in Taiwan, 2003-2006. Pediatrics. 2009; 123:e401-5
3. Wang CL, Wu YT, Liu CA, Kuo HC, Yang KD. Kawasaki disease: infection, immunity and genetics. Pediatr Infect Dis J. 2005;24:998-1004.

4. Kato $H$, Koike S, Yamamoto $M$, Ito $Y$, Yano E. Coronary aneurysms in infants and young children with acute febrile mucocutaneous lymph node syndrome. J Pediatr. 1975;86:892-8.

5. Kuo HC, Huang YH, Chien SC, Yu HR, Hsieh KS, Hsu YW, et al. Genetic variants of CD209 associated with Kawasaki disease susceptibility. PLoS One. 2014;9:e105236

6. Liang CD, Kuo HC, Yang KD, Wang CL, Ko SF. Coronary artery fistula associated with Kawasaki disease. Am Heart J. 2009;157:584-8.

7. Yim D, Curtis N, Cheung M, Burgner D. Update on Kawasaki disease: epidemiology, aetiology and pathogenesis. J Pediatr Child Health. 2013;49: 704-8.

8. Kim HJ, Choi EH, Lim YJ, Kil HR. The usefulness of plateleet-derived microparticle as biomarker of antipaltelet therapy in Kawasaki disease. J Korean Med Sci. 2017:32:147-53.

9. Simon M, Kouskouni E, Vitoratos N, Economou E, Creatsas G. Polymorphisms of platelet glycoprotein receptors and cell adhesion molecules in fetuses with fetal growth restriction and their mothers as detected with pyrosequencing. In Viv. 2017;31:243-50.

10. Weng Z, Li X, Li Y, Lin J, Peng F, Niu W. The association of four common polymorphisms from four candidate genes (COX-1, COX-2, ITGA2B, ITGA2) with aspirin insensitivity: a meta-analysis. PLoS One. 2013;8:e78093.

11. Newburger JW, Takahashl M, Gerber MA, Gewitz MH, Tani LY, Burns JC, et al. Diagnosis, treatment, and long-term management of Kawasaki disease: a statement for health professionals from the committee on Rheumatic Fever, Endocarditis, and Kawasaki Disease, Council on Cardiovascular Disease in the Young, American Heart Association. Pediatrics. 2004:114:1708-13.

12. Che D, Pi L, Xu YF, Fu LY, Zhou HZ, Wang ZP, et al. TBXA2R rs4523 G allele is associated with decreased susceptibility to Kawasaki disease. Cytokine. 2018;111:216-21.

13. Rivera J, Lozano ML, Navarro-Nú-ez L, Vicente V. Platelet receptors and signaling in the dynamics of thrombus formation. Haematologica. 2009;94 700-11.

14. Sixma JJ, van Zanten GH, Huizinga EG, van der Plas RM, Verkley M, Wu YP, et al. Platelet adhesion to collagen: an update. Thromb Haemost. 1997:78: 434-8.

15. Ballesteros F, Tassies D, Reverter JC, Alobid I, Bernal-Sprekelsen M. Idiopathic sudden sensorineural hearing loss: classic cardiovascular and new genetic risk factors. Audiol Neurotol. 2012;17:400-8.

16. Wu GL, Xi YJ, Yao L, Su L, Yan Y, Li MZ, et al. Genetic polymorphism of ITGA2 C807T can increase the risk of ischemic stroke. Int J Neurosci. 2014; 124:841-51.

17. Huo Y, Ley K. Adhesion molecules and atherogenesis. Acta Physiol Scand. 2001:173:35-43.

18. Lu JX, Lu ZQ, Zhang SL, Zhi J, Chen ZP, Wang WX. Polymorphism in integrin ITGA2 is associated with ischemic stroke and altered serum cholesterol in Chinese individuals. Balkan Med J. 2014;31:55-9.

19. Ahn JG, Bae Y, Shin D, Nam J, Kim KY, Kim DS. HMGB1 gene polymorphism is associated with coronary artery lesions and intravenous immunoglobulin resistance in Kawasaki disease. Rheumatology(Oxford). 2019;58:770-5.

20. Matsubara T, Ichiyama T, Furukawa S. Immunological profile of peripheral blood lymphocytes and monocytes/macrophages in Kawasaki disease. Clin Exp Immunol. 2005;141:381-7.

21. Kuo HC, Li SC, Guo MM, Huang YH, Yu HR, Huang FC, et al. Genome-wide association study identifies novel susceptibility genes associated with coronary artery aneurysm formation in Kawasaki disease. PLoS One. 2016;11: e0154943.

22. Zaitsu M, Hamasaki Y, Tashiro K, Matsuo M, Ichimaru T, Fujita I, et al Ulinastatin, an elastase inhibitor, inhibits the increased mRNA expression of prostaglandin H2 synthase-type 2 in Kawasaki disease. J Infect Dis. 2000;181: $1101-9$

23. Furie $B$, Furie BC. Role of platelet P-selectin and microparticle PSGL-1 in thrombus formation. Trends Mol Med. 2004;10:171-8.

24. Hildebrandt P. Natriuretic peptides: prediction of cardiovascular disease in the general population and high risk populations. Dis Markers. 2009; 26:227-33. 
25. Liu YF, Fu LY, Pi L, Che D, Xu YF, Zheng H, et al. An Angiotensinogen Gene Polymorphism (rs5050) Is Associated with the Risk of Coronary Artery Aneurysm in Southern Chinese Children with Kawasaki Disease. Dis Makers. 2019;2019:2849695.

26. Singh S, Vignesh P, Burgner D. The epidemiology of Kawasaki disease: $A$ global update. Arch Dis Child. 2015;100:1084-8.

27. Yanagawa H, Nakamura Y, Yashiro M, Uehara R, Oki I, Kayaba K. Incidence of Kawasaki disease in Japan: the nationwide surveys of 1999-2002. Pediatr Int. 2006;48:356-61.

\section{Publisher's Note}

Springer Nature remains neutral with regard to jurisdictional claims in published maps and institutional affiliations.

Ready to submit your research? Choose BMC and benefit from:

- fast, convenient online submission

- thorough peer review by experienced researchers in your field

- rapid publication on acceptance

- support for research data, including large and complex data types

- gold Open Access which fosters wider collaboration and increased citations

- maximum visibility for your research: over $100 \mathrm{M}$ website views per year

At BMC, research is always in progress.

Learn more biomedcentral.com/submissions 